\title{
The Relationship of von Willebrand Factor Binding to Activated Platelets from Healthy Neonates and Adults
}

\author{
MARKUS SCHMUGGE, MARGARET LUCILLE RAND, KYONG WON ANNIE BANG, \\ MEERA MODY, MICHAEL STEPHEN DUNN, KOFI SARPONG AMANKWAH, \\ VICTOR STANLEY BLANCHETTE, AND JOHN FREEDMAN
}

\begin{abstract}
Division of Haematology/Oncology, The Hospital for Sick Children, Toronto, Ontario, Canada M5G 1X8 [M.S., M.L.R., V.S.B.], Transfusion Medicine, St. Michael's Hospital, Toronto, Ontario, Canada M5B 1W8 [K.W.A.B., M.M., J.F.], Department of Newborn and Development Paediatrics [M.S.D], Department of Obstetrics and Gynaecology [K.S.A.], Sunnybrook and Women's College Health Science Centre, Toronto, Ontario, Canada M5B 1B2, and Departments of Laboratory Medicine and Pathobiology [M.L.R.], Paediatrics [M.S.D., V.S.B.], Obstetrics and Gynaecology [K.S.A.], and Medicine [J.F.], University of Toronto, Toronto, Ontario, Canada M5S $1 A 8$
\end{abstract}

\begin{abstract}
von Willebrand Factor (VWF) is important in platelet adhesion and shear-dependent platelet activation. We performed flow cytometric analyses of VWF binding to and activation of platelets from healthy neonates, children, and adults. Platelets from cord blood ( $n=38$; gestational age: $36-42 \mathrm{wk}$; birth weight: $2.4-5.1 \mathrm{~kg}$ ), neonatal venous blood ( $n=19 ; \mathrm{d} 2-3$ of life), children ( $n=15$; age: $1.5-16.3 \mathrm{y})$, and adults $(n=22$; age: $18-55$ y) were studied. Binding of VWF was assessed using an antihuman VWF polyclonal antibody and a FITC-conjugated secondary antibody. Platelet activation was determined by the expression of CD62P, CD63, CD41, CD42b, activated GPIIb/ IIIa (PAC-1), procoagulant surface (as reflected by annexin $\mathrm{V}$ binding), and microparticle formation. Although the mean percentage of VWF-positive platelets was not significantly higher in unstimulated platelets from 2- to 3-d-old neonates, their platelets were more activated than those from adults, and there was a positive correlation of VWF binding with platelet activation (CD62P: $r=0.74, p<0.001$; annexin V: $r=0.46, p<0.05$ ). In adults, after in vitro activation of platelets with thrombin and
\end{abstract}

Over the past decade, the hemostatic system in neonates has been increasingly well characterized. Compared with adults, neonates have decreased synthesis of many of the

\footnotetext{
Received July 19, 2002; accepted March 20, 2003.

Correspondence: M.L. Rand, Ph.D., Division of Haematology/Oncology, The Hospital for Sick Children, 555 University Avenue, Toronto, Ontario, Canada M5G 1X8; e-mail: margaret.rand@sickkids.ca

M.S. was the recipient of a scholarship (Stipendium zur Förderung des akademischen Nachwuchses) from the University of Zurich, Switzerland, and of a Restracomp fellowship from the Research Institute of The Hospital for Sick Children, Toronto, Canada.

Presented, in part, at the 15th Annual Meeting of the American Society of Pediatric Hematology/Oncology, May 2002, Baltimore, MD, U.S.A.

DOI: 10.1203/01.PDR.0000081294.26060.4B
}

ADP, VWF binding to platelets increased and correlated significantly with CD62P expression $(r=0.71, p<0.001)$. VWF binding to unstimulated neonatal platelets was, however, higher than that to in vitro-stimulated platelets from adults at the same level of expression of platelet activation markers. Further studies are required to assess the mechanism and significance of VWF binding to activated platelets in the neonatal period. (Pediatr Res 54: 474-479, 2003)

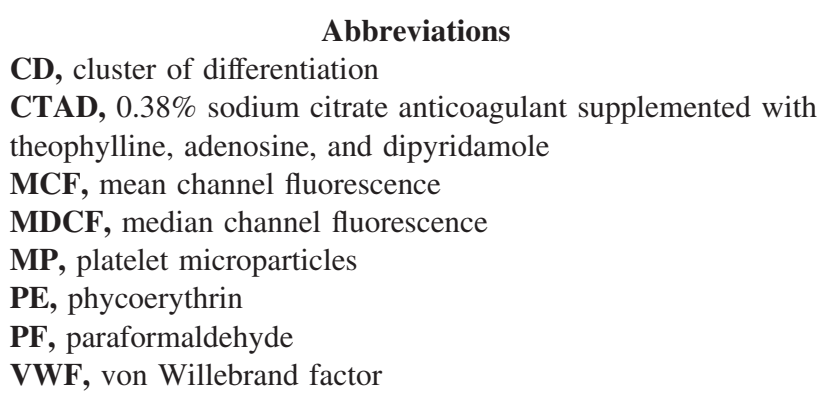

activating and inhibiting coagulation proteins, a lower capacity to generate thrombin, and a reduced fibrinolytic activity (1-6). Clinically, thromboembolic events remain a major cause of morbidity and mortality in hospitalized neonates (7-9). Bleeding occurs in sick premature newborns but is rare in term infants $(10-13)$. Platelet activation pathways in neonates are still not well understood and conflicting data exist on their role in the initiation and propagation of thromboembolic events. Although hyporeactivity in vitro of platelets from neonates has been reported (14-16), the significance of this remains unclear and tests for global platelet function demonstrate hyperreactivity compared with platelets from adults (17-21). 
VWF is a large multimeric plasma glycoprotein synthesized by megakaryocytes and endothelial cells. It plays a key role in the adhesion of platelets to exposed subendothelium, mediates shear-dependent activation of platelets, and increases thrombin generation on the platelet procoagulant surface (22-26). The largest multimers of $\mathrm{VWF}$, with a $M_{\mathrm{r}}>20,000 \mathrm{kD}$, are the most biologically active in the adherence and activation of platelets $(22,23)$. Compared with adults, neonates have been reported to have higher amounts of large multimers of VWF and have increased platelet deposition on the subendothelium in the presence of VWF and increased shear rates (27-29).

Because VWF appears to have a prominent role in neonatal hemostasis, we hypothesized that VWF binding to platelets is increased in neonates compared with children and adults. Hence, we examined VWF-platelet binding and its relationship to platelet activation, and to plasma VWF, in healthy neonates (cord and venous blood), in comparison to children and adults.

\section{METHODS}

Study subjects. Healthy neonates, children, and adults were examined.

Neonatal samples were obtained from cord blood (neonatescord) from 38 healthy, term neonates (18 males and 20 females), with a mean gestational age of $39.3 \mathrm{wk}$ (range, 36-42 wk) and a mean birth weight of $3515 \mathrm{~g}$ (range, 2440-5098 g; all >10th weight percentile); 18 were delivered vaginally and 20 were born by cesarean section. Thirty-seven out of 38 had a 1-min Apgar score $\geq 7$ and a 5-min score $\geq 9$. One baby, delivered vaginally, had an Apgar score of 6 at $1 \mathrm{~min}$ and 9 at $5 \mathrm{~min}$. Samples were also obtained from neonates $(n=19)$ studied on d 2-3 of life (neonates ${ }_{2-3}$ d); 15 were repeat samples from the

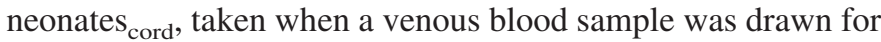
the Guthrie test at a mean of $39 \mathrm{~h}$ (range, 27-53 h) after delivery, and four were neonates studied only once, at $42 \mathrm{~h}$ (range, 28-48 h) post delivery.

In addition, two control groups were studied: Healthy children ( $n=15$; nine males, six females), with a mean age $9.6 \mathrm{y}$ (range, 1.5-16.3 y) were recruited from the phlebotomy clinic of The Hospital for Sick Children, Toronto, where they were having blood samples drawn for elective surgery, family studies, or long-term follow-up after completion of treatment. Healthy adults ( $n=22$; eight males, 14 females) with a mean age of $37 \mathrm{y}$ (range, 18-55 y) were laboratory volunteers.

No subject had ingested drugs known to affect platelet function in the $2 \mathrm{wk}$ preceding blood donation. Informed consent was obtained for all subjects and the study was approved by the hospitals' research ethics boards.

Blood samples. Cord blood samples, collected within $5 \mathrm{~min}$ of delivery, were taken via a 21-gauge needle into a polypropylene syringe and then transferred immediately into $3.8 \%$ (final concentration) sodium citrate or CTAD (Diatube-H, BD Biosciences, San Jose, CA, U.S.A.). For neonates ${ }_{2-3}$ d, venous blood was collected using a loose tourniquet and, after discard of the first $1 \mathrm{~mL}$, by dripping from a 21-gauge needle placed in a peripheral vein on the back of the hand, directly into polypropylene tubes containing sodium citrate or CTAD. Venous blood from the children and adults was collected from an antecubital vein with a 21-gauge needle using a loose tourni- quet, after discard of the initial $2 \mathrm{~mL}$, into vacutainers containing sodium citrate or CTAD.

In some cases, as indicated below, $0.1 \mathrm{~mL}$ of the CTAD blood was immediately fixed with an equal volume of $1 \%$ (wt/vol) PF, as described elsewhere (30). All samples were maintained at room temperature for $1-6 \mathrm{~h}$ until processing for flow cytometry; over this time period, platelets taken into CTAD anticoagulant remained in a resting state comparable to that seen with fixed platelets (30).

VWF antigen levels and VWF multimer distribution. VWF antigen levels in citrated plasma were measured by a Rellplate electroimmunodiffusion kit (American Diagnostics, Seattle, WA, U.S.A.). The multimeric distribution of VWF was analyzed by separating the multimers by SDS-1.5\% agarose gel electrophoresis as described $(31,32)$, and determining the relative proportions of low (1- to 5-mers), intermediate (6- to 10 -mers), and large ( $>10$-mers) multimers of VWF by densitometry.

Flow cytometric assessment of platelets in whole blood. FITC-conjugated MAb to CD41 [platelet glycoprotein (GP) IIb/IIIa complex] and CD42b (GPIb), and PE-conjugated MAb to CD41 and CD63 (lysosomal membrane protein), were obtained from Beckman Coulter, Inc. (Fulleron, CA, U.S.A.). FITC-labeled PAC-1 (MAb against the activation-induced, conformationally changed neoepitope on GPIIb/IIIa) was from $\mathrm{BD}$ Biosciences, as were PE-conjugated anti-CD62P (Pselectin; an $\alpha$-granule membrane protein expressed on the platelet surface after activation), and PE-labeled annexin V (which binds to the procoagulant phosphatidylserine expressed on the surface of activated platelets).

Flow cytometric analysis was performed as described elsewhere $(30,33)$. In brief, $5-\mu \mathrm{L}$ aliquots of unfixed or $10 \mu \mathrm{L}$ of fixed blood taken into CTAD were incubated with $5 \mu \mathrm{L}$ of $\mathrm{MAb}$ and $50 \mu \mathrm{L}$ of buffer [145 mM NaCl, $5 \mathrm{mM} \mathrm{KCl}, 1 \mathrm{mM}$ $\mathrm{MgCl}, 10 \mathrm{mM}$ HEPES ( $N$-2-hydroxyethylpiperazine- $N$ '-2ethanesulfonic acid), containing $2.0 \mathrm{mM} \mathrm{Mg}^{++}$]. Annexin V staining was performed in the presence of $2 \mathrm{mM} \mathrm{Ca}^{++}$and $\mathrm{Mg}^{++}$, and $2.5 \mathrm{mM}$ Gly-Pro-Arg-Pro (GPRP) (Sigma Chemical, St. Louis, MO, U.S.A.) was added to the samples to prevent fibrin polymerization. After $30 \mathrm{~min}$ incubation at $22^{\circ} \mathrm{C}$ in the dark, samples were fixed with $1 \% \mathrm{PF}$ for a further $15 \mathrm{~min}$ and $1 \mathrm{~mL}$ filtered FACSFlow fluid (BD Biosciences) was added. The samples were then acquired using a FACSCalibur flow cytometer (BD Biosciences) equipped with a $15-\mathrm{mW}$ argon ion laser. Gating on forward light scatter and fluorescence, CD41- and CD42b-positive single platelets were identified; 10,000 events were acquired on each sample and analyzed using CellQuest software (BD Biosciences). Platelet MP were distinguished from intact normal platelets on the basis of the characteristic flow cytometric profile of forward light scatter versus fluorescence, as previously described (34). The percentage of MP was defined as that proportion of all CD41positive cells that were smaller than $0.8 \mu \mathrm{m}$. Results are expressed as MDCF for CD41 and CD42b expression, or as the percentage of platelets expressing CD62P or CD63, or binding PAC-1 or annexin V.

In vitro activation of platelets from adults. To evaluate the ability of activated platelets from adults to bind VWF, citrated- 
whole blood was exposed to thrombin $(0.1$ or $1 \mathrm{U} / \mathrm{mL})$ or ADP (5 or $10 \mu \mathrm{M}$ ) before fixation and staining, as described elsewhere $(30,33)$. In brief, $45 \mu \mathrm{L}$ of citrated blood was diluted $1: 1$ with buffer, incubated with $2.5 \mathrm{mM}$ GPRP and thrombin or ADP for $10 \mathrm{~min}$ at $37^{\circ} \mathrm{C}$, and then fixed with $1 \% \mathrm{PF}$ for $10 \mathrm{~min}$. After dilution with $1 \mathrm{~mL}$ PBS, $50 \mu \mathrm{L}$ of the sample were stained with the antibodies as described above. For annexin $\mathrm{V}$ staining and platelet-VWF binding, $5 \mu \mathrm{L}$ of activated, unfixed whole blood was used.

Platelet-VWF binding. The flow cytometric method of Chow et al. (35) was applied, with modifications. Fivemicroliter aliquots of CTAD-whole blood were incubated with $50 \mu \mathrm{L}$ of buffer containing $2 \mathrm{mM} \mathrm{Mg}^{++}$and $1.5 \mu \mathrm{L}$ of rabbit antihuman VWF polyclonal antibody (1:100 dilution; Sigma Chemical) for $2 \mathrm{~min}$, and then $10 \mu \mathrm{L}$ of FITC-labeled goat anti-rabbit IgG (1:100 dilution; Sigma Chemical) and $5 \mu \mathrm{L}$ of PE-conjugated anti-CD41 for $30 \mathrm{~min}$. The stained samples were fixed with $1 \% \mathrm{PF}$, diluted with $1 \mathrm{~mL}$ of FACSFlow, and acquired as described above. The binding results for VWF are expressed as MCF of VWF-positive single platelets (reflecting epitope density) and also as the percentage of platelets expressing the antigen (\%VWF). As positive controls, VWF-positive platelets were produced by adding $4 \mathrm{mg} / \mathrm{mL}$ of the snake venom protein botrocetin (Pentapharm, Basel, Switzerland) $(36,37)$.

To measure the binding of released VWF from platelets, washed platelets from adults were prepared by centrifuging citrated whole blood at $150 \times g$ for $10 \mathrm{~min}$ to obtain plateletrich plasma, which was then centrifuged at $500 \times g$ for $10 \mathrm{~min}$. The platelets were resuspended in PBS containing 1\% BSA, centrifuged again at $500 \times g$ for $10 \mathrm{~min}$ and resuspended in the same buffer. The platelet suspension was incubated with 1.25 $\mathrm{mM}$ GPRP in the absence or presence of $1 \mathrm{U} / \mathrm{mL}$ thrombin for $30 \mathrm{~min}$ at $22^{\circ} \mathrm{C}$. The thrombin-stimulated washed platelets were then incubated for 20 min with rabbit antihuman VWF polyclonal antibody and processed as above.

Statistical analysis. Unless otherwise indicated, values reported are means \pm SEM. Statistical analyses were performed using the GraphPad Prism 3.0 program (GraphPad Software, San Diego, CA, U.S.A.). Comparison of the study groups was by paired $t$ tests or ANOVA and the Bonferroni test. The correlation between markers of platelet activation (percentage CD62P and CD63 expression, and percentage annexin V binding) and percentage VWF binding was assessed by the Pearson correlation coefficient. Differences were considered statistically significant at $p<0.05$.

\section{RESULTS}

Platelet-bound $\boldsymbol{V W F}$. With unstimulated platelets, there was no significant difference in the mean percentage of VWFpositive platelets between the four groups, although the mean tended to be higher in the neonates ${ }_{2-3}$ d group (Fig. 1). The mean MDCF values, reflecting epitope density, also did not differ significantly between the groups (data not shown). As shown in Figure $2 A$ and Table 1 , in the neonates ${ }_{2-3}$ d group only, a significant correlation was observed between platelet activation, as reflected by the proportion of platelets expressing

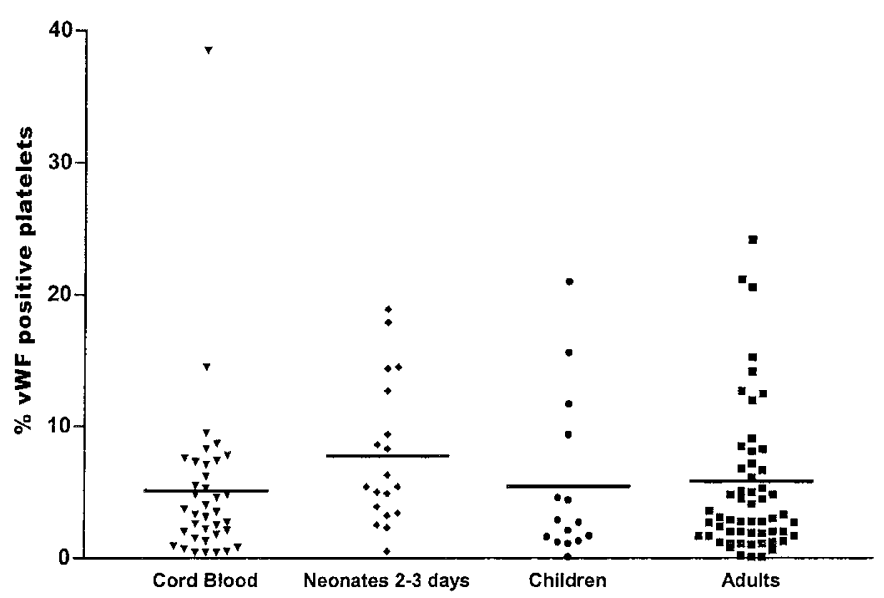

Figure 1. Percentage of VWF-positive platelets in unstimulated whole blood samples from cord blood, 2- to 3-d-old neonates, children, and adults. The horizontal line represents the mean value.
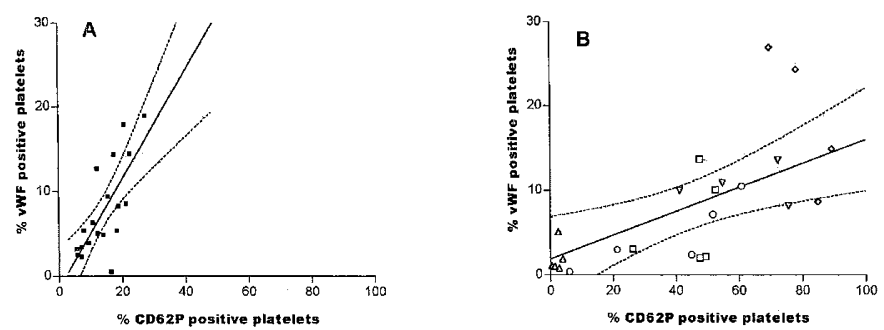

Figure 2. (A) Correlation and linear regression of percentage of VWFpositive platelets and CD62P-positive platelets from 2- to 3-d-old neonates, as determined by Pearson analysis $(r=0.74, p<0.001)$. Dashed lines represent $95 \%$ confidence intervals. $(B)$ Correlation and linear regression of percentage of VWF-positive platelets and CD62P-positive platelets from unstimulated and in vitro-stimulated whole blood samples from five adults $(r=0.71, p<$ 0.001). Dashed lines represent $95 \%$ confidence intervals. Pooled data from the results of different activators, i.e. 0.1 (inverted triangles) and $1 \mathrm{U}$ (diamonds) thrombin, 5 (circles) and 10 (squares) $\mu \mathrm{M}$ ADP, and from unstimulated platelets (triangles) were used.

Table 1. Correlation (r) of markers of platelet activation and percentage of VWF-positive platelets in cord blood, 2- to 3-d-old neonates, children, and adults

\begin{tabular}{lccc}
\hline & \multicolumn{3}{c}{ Correlation between \% VWF and } \\
\cline { 2 - 4 } & $\%$ CD62P & \% CD63 & \% Annexin V \\
\hline All subjects & 0.04 & 0.02 & 0.01 \\
Neonates $_{\text {cord }}$ & 0.03 & 0.15 & 0.04 \\
Neonates $_{2-3}$ d & $0.74 \S$ & $0.43^{*}$ & $0.46^{* *}$ \\
Children $_{\text {Adults }}$ & 0.15 & 0.12 & $0.63^{* *}$ \\
\hline
\end{tabular}

Correlation $(r)$ was determined by Pearson analysis.

$* p=0.06 ; * * p<0.05 ; \S p<0.001$.

CD62P and annexin $\mathrm{V}$ binding, and the percentage of VWFpositive platelets ( $p<0.001$ and $p<0.05$, respectively); the correlation did not reach statistical significance with percentage of CD63 expression ( $p=0.06$ ). In the control group of children, the correlation between platelet-bound VWF and annexin $\mathrm{V}$ binding was also significant $(p<0.05)$, but the percentage of VWF-positive platelets did not correlate significantly with the other markers of platelet activation (Table 1). In contrast to neonates ${ }_{2-3}$ and children, no significant correlations were observed with unstimulated platelets from adults. 
Because we observed little VWF binding to unstimulated platelets from adults, platelet-VWF binding was assessed in adults with platelets stimulated with thrombin or $\operatorname{ADP}(n=5)$. An increased binding of VWF to platelets stimulated with 0.1 or $1 \mathrm{U} / \mathrm{mL}$ thrombin was observed; the increase in VWF binding to platelets stimulated with 5 or $10 \mu \mathrm{M}$ ADP was smaller, despite CD62P positivity of $25-60 \%$ (Fig. 2B). Combining the results for unstimulated and stimulated platelets from this group of adults, there was a highly significant correlation between platelet-VWF binding and platelet activation (for CD62P: $r=0.71, p<0.001$, Fig. 2B; for CD63: $r=$ $0.78, p<0.0001)$. Comparison of the correlation slopes in Figure 2, $A$ and $B$, indicates that VWF binding to neonatal platelets was higher than that to adult platelets at the same levels of platelet activation.

Plasma and platelet $\alpha$-granule $V W F$. Increased plateletbound VWF could result from increased VWF levels in plasma. We found, however, that mean VWF antigen levels were not significantly different between neonates ${ }_{\text {cord }}$, neonates $_{2-3}$ d , adults, and children (Table 2). We did observe that the largest multimers of VWF made up $31 \%$ of the total amount of VWF in neonates ${ }_{2-3}$ d, compared with only $23 \%$ in adults $(p<0.05)$ (Table 2$)$.

Platelet-bound VWF may also originate from VWF released from platelet $\alpha$-granules upon platelet stimulation. We found, in seven healthy adult volunteers, that the MCF of bound VWF was $1.98 \pm 0.36$-fold higher with thrombin-stimulated washed platelets than with baseline, unstimulated, platelets $(p<0.05)$.

Expression of markers of platelet activation. In neonates ${ }_{2-3 \mathrm{~d}}$ and adults, platelet-bound VWF correlated with activation of platelets as measured by CD62P expression. Because different mechanisms of platelet activation may be reflected by different markers of platelet activation $(33,38,39)$, we also tested other markers of platelet activation in the four groups of subjects examined. As shown in Table 3, there was no significant difference in activation status of unstimulated platelets from the control groups of children and adults. In contrast, compared with adults, CD63 expression and MP generation were increased in neonates cord $_{\text {c }}\left(p<0.001\right.$ for both) and neonates ${ }_{2-3} \mathrm{~d}$ $(p<0.001$ for both). CD62P expression and annexin $\mathrm{V}$ binding were also increased in neonates ${ }_{2-3} \mathrm{~d}(p<0.001$ for both), but in neonates ${ }_{\text {cord }}$, the increase did not reach statistical significance. As also shown in Table 3, no significant differences between the four groups were seen in the expression of CD42b. However, CD41 expression was reduced in neonates $_{2-3}$ d $(p<0.001)$. PAC-1 binding was similar in all groups.
Table 3. Baseline platelet activation as determined by flow cytometry in cord blood samples from newborns and venous blood samples from 2- to 3-d-old neonates, children, and adults

\begin{tabular}{lcccc}
\hline & $\begin{array}{c}\text { Neonates }_{\text {cord }} \\
(n=38)\end{array}$ & $\begin{array}{c}\text { Neonates }_{2-3} \text { d } \\
(n=19)\end{array}$ & $\begin{array}{c}\text { Children } \\
(n=15)\end{array}$ & $\begin{array}{c}\text { Adults } \\
(n=22)\end{array}$ \\
\hline CD62P (\%) & $6.9 \pm 0.7$ & $14.2 \pm 1.4^{*}$ & $5.3 \pm 0.8$ & $3.5 \pm 0.3$ \\
CD63 (\%) & $3.6 \pm 0.4^{*}$ & $5.3 \pm 0.9^{*}$ & $2.3 \pm 0.4$ & $1.8 \pm 0.1$ \\
PAC-1 (\%) & $1.7 \pm 0.4$ & $1.0 \pm 0.3$ & $0.9 \pm 0.2$ & $1.1 \pm 0.1$ \\
Annexin V (\%) & $3.0 \pm 0.5$ & $4.6 \pm 1.2^{*}$ & $2.1 \pm 0.3$ & $1.2 \pm 0.2$ \\
Microparticles (\%) & $6.3 \pm 0.6^{*}$ & $8.4 \pm 0.9^{*}$ & $4.2 \pm 0.7$ & $3.0 \pm 0.2$ \\
CD41 (MDCF) & $365 \pm 9.9$ & $328 \pm 6.6^{*}$ & $396 \pm 15.5$ & $392 \pm 9.3$ \\
CD42b (MDCF) & $171 \pm 5.9$ & $160 \pm 4.7$ & $160 \pm 6.7$ & $166 \pm 4.8$ \\
\hline
\end{tabular}

Values are means \pm SEM.

$* p<0.001$ compared with adults.

\section{DISCUSSION}

Using flow cytometry, we assessed VWF binding to platelets, and its relationship to platelet activation, in neonates, children, and adults. There was no difference between the groups in the proportion of platelets demonstrating surfacebound VWF. However, we showed, for the first time, that platelet-bound VWF increases with platelet activation. In the unstimulated platelets from neonates ${ }_{2-3}$ d that were already mildly activated at baseline, platelet-bound VWF correlated with CD62P expression and with annexin V binding. Because unstimulated platelets from adults showed little activation, platelets from adults were stimulated in vitro to achieve increased expression of activation markers. VWF binding to platelets from adults was found to increase after stimulation with thrombin and ADP, and the increase correlated with the level of expression of CD62P and CD63. The proportion of in vitro-stimulated platelets from adults demonstrating surfacebound VWF was, however, consistently lower than that of the mildly activated platelets from neonates ${ }_{2-3 \mathrm{~d}}$ at the same levels of expression of platelet activation markers (Fig. $2 B$ versus Fig. $2 A)$.

A portion of circulating VWF is stored in the platelet $\alpha$-granules. The stored VWF is released during activation and can bind to platelets $(40,41)$. We confirmed these previous observations, in that we demonstrated a small but significant increase in the binding of anti-VWF antibody after in vitro activation of washed platelets from adults. It may be, then, that at least part of the VWF binding seen in our study arises from binding of VWF released from the $\alpha$-granules during platelet activation.

Although others have reported higher levels of plasma VWF in newborns $(4,5)$, we observed no significant increase in plasma VWF antigen levels in neonates $2-3 \mathrm{~d}$ that could account

Table 2. VWF antigen levels and percentage of large (>10-mers) multimers of VWF in cord blood samples from newborns and venous blood samples from 2- to 3-d-old neonates, children, and adults

\begin{tabular}{lcccc}
\hline & Neonates $_{\text {cord }(n=38)}$ & Neonates $_{2-3 \mathrm{~d}}(n=19)$ & Children $(n=15)$ & Adults $(n=22)$ \\
\hline VWF antigen $(\mathrm{U} / \mathrm{mL})$ & $1.16 \pm 0.05(0.51-1.85)$ & $1.04 \pm 0.06(0.65-1.72)$ & $0.94 \pm 0.07(0.54-1.6)$ & $0.98 \pm 0.07(0.48-2.8)$ \\
Percentage of large multimers of VWF & $21 \pm 1.7 \%(8-42 \%)$ & $31 \pm 1.6 \% *(19-41 \%)$ & $22 \pm 2.4 \%(13-27 \%)$ & $23 \pm 2.3 \%(6-39 \%)$ \\
\hline
\end{tabular}

Values are means \pm SEM, with minimum-maximum values in parentheses.

$* p<0.05$ compared with adults. 
for the correlation of VWF binding with mild activation of platelets in this study group. In agreement with others $(27,28)$, we observed an increased proportion of large VWF multimers in neonates ${ }_{2-3}$; the presence of higher levels of these more active multimers of VWF could lead to increased platelet adhesion even in conditions when shear rates are only mildly elevated. It may be that this increased proportion of large VWF multimers is due to their release from endothelial WeibelPalade bodies (42) as a result of the endothelial lesion brought about by the venipuncture in the neonates ${ }_{2-3}$ d (see below). Hence, the correlation of VWF binding with platelet activation may be related to a higher proportion of large VWF multimers in this group. Whether differences in the proportion of large VWF multimers relate to differences in the activity of the newly described VWF cleaving protease $(43,44)$ is not known at present.

Our study was not designed to identify the binding site for VWF on the platelet surface. In botrocetin-stimulated platelets $(36,37,45)$ that were used as positive controls in the present study, the majority of VWF binds to the GPIb/V/IX complex. Although blood sampling was not done under conditions of high shear rates, that can enhance binding of VWF to the $\mathrm{GPIb} / \mathrm{V} / \mathrm{IX}$ receptor complex, it has been reported that binding of VWF to GPIb/V/IX can be observed even at low shear $\left(<500 \mathrm{~s}^{-1}\right)(22-24,46)$. We found no differences in GPIb/IX (CD42) expression among the groups studied, even though mild platelet activation led to increased VWF binding in the neonates $_{2-3 \mathrm{~d}}$ group. VWF can also bind to the integrin GPIIb/ IIIa, because clustering of GPIb/V/IX on the membrane of platelets activated by chemical agonists or multimeric VWF enhances the ability of GPIIb/IIIa to bind VWF and fibrinogen (47). Our finding that expression of GPIIb/IIIa (CD41) is significantly reduced on the surface of platelets from neonates $_{2-3 \mathrm{~d}}$, in agreement with others $(48,49)$, whereas plateletbound VWF increases with activation further supports the possibility that this increase may be related to the higher proportion of large VWF multimers in this group. That our findings were not the result of an increase in the altered conformation of activated GPIIb/IIIa was shown by the low levels of PAC-1 binding. In preliminary experiments with platelets from adults and MAb designed to block specific VWF binding sites on GPIb and GPIIb/IIIa [AP-1 and AP-2 (50), respectively, a generous gifted from Dr. R.R. Montgomery, Milwaukee, WI, U.S.A.], we were unable to clearly determine to which receptor the majority of VWF binds.

We found an increased expression of activation markers on platelets from neonates ${ }_{2-3} \mathrm{~d}$ compared with those from adults. In contrast, it has been reported that neonatal platelets are hyporeactive upon in vitro stimulation on the first days after delivery $(14,48,51,52)$, with normalization by at least $10 \mathrm{~d}$ after delivery (53). Preanalytical aspects of our study deserve consideration because these could affect the results we have obtained. We cannot, at present, exclude the possibility that part of the increased activation seen in the platelets from neonates ${ }_{2-3}$ was due to activation during blood sampling, i.e. dripping blood from a needle placed in a small peripheral vein on the back of the hand. The different ages and sizes of the study subjects made it impossible to perform this study using identical blood sampling methods in all study groups. However, in five healthy adults, blood sampling into vacutainers was compared with dripping blood from a needle, and we found no significant difference in expression of CD62P or CD63, or binding of annexin $\mathrm{V}$ between the two sampling methods. Thus, it may be that the mild activation of neonatal platelets observed in this study results from the actual venipuncture of a small neonatal vessel, rather than from collecting blood by dripping it from a needle. Analytical aspects of our study deserve consideration as well. It is also possible that differences in antigen-antibody binding kinetics may, at least in part, lead to some of the differences we observed in plateletVWF binding with increasing platelet activation. However, quantitation of such kinetics was beyond the scope of this study and remains to be investigated.

\section{CONCLUSION}

In conclusion, we found that platelet activation correlates with binding of VWF to platelets. In neonates, this correlation was demonstrated with the mildly activated platelets seen at baseline. In adults, such correlation was shown only after in vitro activation. Further studies are required to determine the mechanism and significance of VWF binding to activated platelets in the neonatal period.

Acknowledgments. The authors thank Dr. Lillian Sung for help with statistical analysis and Dr. Sara Israels for helpful discussions during preparation of the manuscript.

\section{REFERENCES}

1. Andrew M, Vegh P, Johnston M, Bowker J, Ofosu F, Mitchell L 1992 Maturation of the hemostatic system during childhood. Blood 80:1998-2005

2. Andrew M 2000 Developmental hemostasis: relevance to thromboembolic complications in pediatric patients. In: Andrews M, Monagle PT, Brooker L (eds) Thromboembolic Complications During Infancy and Childhood. BC Decker, Hamilton, ON, Canada pp 5-46

3. Hathaway W, Corrigan J 1991 Report of scientific and standardization subcommittee on neonatal hemostasis. Thromb Haemost 65:323-325

4. Andrew M, Paes B, Milner R 1990 Development of the hemostatic system in the neonate and young infant. J Pediatr Hematol Oncol 12:95-104

5. Andrew M, Paes B, Johnston M 1987 Development of the human coagulation system in the full term infant. Blood 70:165-172

6. Andrew M, Mitchell L, Vegh P, Ofosu F 1994 Thrombin regulation in children differs from adults in the absence and presence of heparin. Thromb Haemost 72:836-842

7. Schmidt B, Andrew M 1996 Neonatal thrombosis: report of a prospective Canadian and international registry. Pediatrics 96:939-943

8. Nowak-Göttl U, von Kries R, Göbel U 1997 Neonatal symptomatic thromboembolism in Germany: two year survey. Arch Dis Child 76:F163-F167

9. Andrew M 2000 Epidemiology of venous thromboembolic events. In: Andrews M, Monagle PT, Brooker L (eds) Thromboembolic Complications During Infancy and Childhood. BC Decker, Hamilton, ON, Canada, pp 111-164

10. Andrew M 1997 The relevance of development hemostasis to hemorrhagic disorders of newborns. Semin Perinatol 21:70-85

11. Ahmann PA, Lazzara A, Dykes FD, Brann Jr AW, Schwartz JF 1980 Intraventricular hemorrhage in the high risk preterm infant: incidence and outcome. Ann Neurol 7:118-124

12. DeSa DJ, MacLean BS 1970 An analysis of massive pulmonary haemorrhage in the newborn infant in Oxford, 1948-68. J Obstet Gynaecol Br Commonw 77:158-163

13. Hayden Jr CK, Shattuck KE, Richardson CJ, Ahrendt DK, House R, Swischuk LE 1985 Subependymal germinal matrix hemorrhage in full-term neonates. Pediatrics 75:714-718

14. Rajasekhar D, Kestin AS, Bednarek FJ, Ellis PA, Barnard MR, Michelson AD 1994 Neonatal platelets are less reactive than adult platelets to physiological agonists in whole blood. Thromb Haemost 72:953-963

15. Ts'ao CH, Green D, Schultz K 1976 Function and ultrastructure of platelets of neonates: enhanced ristocetin aggregation of neonatal platelets. $\mathrm{Br} \mathrm{J}$ Haematol 32:225-233

16. Mull MM, Hathaway WE 1970 Altered platelet function in newborns. Pediatr Res $4: 229-237$ 
17. Andrew M, Paes B, Bowker J, Vegh P 1990 Evaluation of an automated bleeding time device in the newborn. Am J Hematol 335:275-277

18. Sutor AH 1998 The bleeding time in pediatrics. Semin Thromb Hemost 24:531-543

19. Carcao MD, Blanchette VS, Dean JA, He L, Kern MA, Stain AM, Sparling CR, Stephens D, Ryan G, Freedman J, Rand ML 1998 The Platelet Function Analyze (PFA-100): a novel in-vitro system for evaluation of primary haemostasis in children. Br J Haematol 101:70-73

20. Israels SJ, Cheang T, McMillan-Ward EM, Cheang M 2001 Evaluation of primary hemostasis in neonates with a new in vitro platelet function analyzer. J Pediatr 138:116-119

21. Roschitz B, Sudi K, Koestenberger M, Muntean W 2001 Shorter PFA 100 closure times in neonates than in adults: role of red cells, white cells and von Willebrand factor. Acta Paediatr 90:664-670

22. Sadler JE 1998 Biochemistry and genetics of von Willebrand factor. Annu Rev Biochem 67:395-424

23. Moake JL, Turner NA, Stathopoulos NA, Nolasco LH, Hellums JD 1986 Involvemen of large plasma von Willebrand factor (VWF) multimers and unusually large VWF forms derived from endothelial cells in shear stress-induced platelet aggregation. J Clin Invest 78:1456-1461

24. McCrary JK, Nolasco LH, Hellums JD, Kroll MH, Turner NA, Moake JL 1995 Direct demonstration of radiolabeled von Willebrand factor binding to platelet glycoprotein $\mathrm{Ib}$ and IIb-IIIa in the presence of shear stress. Ann Biomed Eng 23:787-793

25. Ruggeri ZM 1999 Structure and function of von Willebrand factor. Thromb Haemos $82: 576-584$

26. Keularts IM, Hamulyak K, Hemker HC, Beguin S 2000 The effect of DDAVP infusion on thrombin generation in platelet-rich plasma of von Willebrand Type 1 and mild haemophilia A patients. Thromb Haemost 84:638-642

27. Katz JA, Moake JL, McPherson PD, Weinstein MJ, Moise KJ, Carpenter RJ, Sala DJ 1989 Relationship between human development and disappearance of unusually large von Willebrand factor multimers from plasma. Blood 73:1851-1858

28. Weinstein J, Blanchard R, Moake J, Vosburgh E, Moise K 1989 Fetal and neoanta von Willebrand factor is unusually large and similar to the VWF in patients with TTP. Br J Haematol 72:68-72

29. Shenkman B, Linder N, Savion N, Tamarin I, Dardik R, Kennet G, German B, Varon D 1999 Increased neonatal platelet deposition on subendothelium under flow conditions: the role of plasma von Willebrand factor. Pediatr Res 45:270-275

30. Kühne T, Hornstein A, Chang W, Semple J, Blanchette V, Freedman J 1995 Flow cytometric evaluation of platelet activation in blood collected into EDTA vs. Diatube $\mathrm{H}$, a sodium citrate solution supplemented with theophylline, adenosine, and dipyridamole. Am J Hematol 50:40-45

31. Ledford MR, Kent JW, Civantos F 1990 A comparative study of three methods for the visualization of von Willebrand factor multimers. Thromb Haemost 64:569-575

32. Aihara M, Sawada Y, Ueno K, Morimoto S, Yoshida Y, de Serres M, Cooper HA, Wagner RH 1986 Visualization of von Willebrand factor multimers by immunoenzymatic stain using avidin-biotin peroxidase complex. Thromb Haemost 55:263-267

33. Freedman J, Mody M, Lazarus AH, Dewar L, Song S, Blanchette VS, Garvey MB Ofosu FA 2002 Platelet activation and hypercoagulability following treatment with porcine factor VIII (HYATE:C). Am J Hematol 69:192-199

34. Abrams CS, Ellison N, Budzynski AZ, Shattil SJ 1990 Direct detection of activated platelets and platelet-derived microparticles in humans. Blood 75:128-138

35. Chow TW, Turner NA, Chintagumpala M, McPherson PD, Nolasco LH, Rice L, Hellums JD, Moake JL 1998 Increased von Willebrand factor binding to platelets in single episode and recurrent types of thrombotic thrombocytopenic purpura. Am J Hematol 57:293-302
36. Andrews RK, Booth WJ, Gorman JJ, Castaldi PA, Berndt MC 1989 Purification of botrocetin from Bothrops jararaca venom. Analysis of the botrocetin-mediated interaction between von Willebrand factor and the human platelet membrane glycoprotein Ib-IX complex. Biochemistry 28:8317-8326

37. Girma JP, Takahashi Y, Yoshioka A, Diaz J, Meyer D 1990 Ristocetin and botrocetin involve two distinct domains of von Willebrand factor for binding to platelet membrane glycoprotein Ib. Thromb Haemost 64:326-332

38. Chang H, Mody M, Lazarus AH, Ofosu F, Garvey MB, Blanchette V, Teitel J, Freedman J 1998 Platelet activation induced by porcine factor VIII (Hyate:C). Am J Hematol 57:200-205

39. Song S, Mody M, Freedman J, Ellis J, Lazarus AH 2003 von Willebrand factor (VWF)-dependent human platelet activation: porcine VWF utilizes different transmembrane signaling pathways than does thrombin to activate platelets, but both require protein phosphatase function. J Thromb Haemost 1:337-346

40. Parker RI, Gralnick HR 1986 Identification of platelet glycoprotein IIb/IIIa as the major binding site for released platelet-von Willebrand factor. Blood 68:732-736

41. Gralnick HR, Williams SB, McKeown LP, Magruder L, Hansmann K, Vail M, Parker RI 1991 Platelet von Willebrand factor. Mayo Clin Proc 66:634-640

42. Wagner DD 1993 The Weibel-Palade body: the storage granule for von Willebrand factor and P-selectin. Thromb Haemost 70:105-110

43. Mannucci PM, Canciani MT, Forza I, Lussana F, Lattuada A, Rossi E 2001 Changes in health and disease of the metalloprotease that cleaves von Willebrand factor. Blood 98:2730-2735

44. Levy GG, Nichols WC, Lian EC, Foroud T, McClintick JN, McGee BM, Yang AY, Siemieniak DR, Stark KR, Gruppo R, Sarode R, Shurin SB, Chandrasekaran V, Stabler SP, Sabio H, Bouhassira EE, Upshaw Jr JD, Ginsburg D, Tsai HM 2001 Mutations in a member of the ADAMTS gene family cause thrombotic thrombocytopenic purpura. Nature 413:488-494

45. Sugimoto M, Mohri H, McClintock RA, Ruggeri ZM 1991 Identification of discontinuous von Willebrand factor sequences involved in complex formation with botrocetin. A model for the regulation of von Willebrand factor binding to platelet glycoprotein Ib. J Biol Chem 266:18172-18178

46. Kulkarni S, Dopheide SM, Yap CL, Ravanat C, Freund M, Mangin P, Heel KA, Street A, Harper IS, Lanza F, Jackson SP 2000 A revised model of platelet aggregation. $\mathrm{J}$ Clin Invest 105:783-791

47. Kasirer-Friede A, Ware J, Leng L, Marchese P, Ruggeri ZM, Shattil SJ 2002 Lateral clustering of platelet GP Ib-IX complexes leads to up-regulation of the adhesive function of integrin alpha IIb beta 3. J Biol Chem 277:11949-11956

48. Hurtaud-Roux MF, Hezard N, Lefranc V, Foucart C, Desanges C, Aujard Y, Simon G, Cand M, Rambaldini A, Droulle C, N'Guyen P, Potron G, Schlegel N 2001 Quantification of the major integrins and p-selectin in neonatal platelets by flow cytometry. A bi-centric study. Thromb Haemost 86(suppl):284a

49. Simak J, Holada K, Janota J, Stranak Z 1999 Surface expression of major membrane glycoproteins on resting and TRAP-activated neonatal platelets. Pediatr Res 46:445449

50. Ruggeri ZM, De Marco L, Gatti L, Bader R, Montgomery RR 1983 Platelets have more than one binding site for von Willebrand factor. J Clin Invest 72:1-12

51. Pietrucha T, Wojciechowski T, Greger J, Jedrzejewska E, Nowak S, Chrul S, Golanski J, Watala C 2001 Differentiated reactivity of whole blood neonatal platelets to various agonists. Platelets 12:99-107

52. Gatti L, Guarneri D, Caccamo ML, Gianotti GA, Marini A 1996 Platelet activation in newborns detected by flow-cytometry. Biol Neonate 70:322-327

53. Tanindi S, Kurekci AE, Koseoglu V, Kurt M, Ozcan O 1995 The normalization period of platelet aggregation in newborns. Thromb Res 80:57-62 